\title{
Don't Have a Cow, Man: Consumer Acceptance of Animal-Free Dairy Products in Five Countries
}

\author{
Oscar Zollman Thomas ${ }^{1 *}$ and Christopher Bryant ${ }^{2}$ \\ ${ }^{1}$ Formo, Berlin, Germany, ${ }^{2}$ Department of Psychology, University of Bath, Bath, United Kingdom
}

OPEN ACCESS

Edited by:

Elena Horská, Slovak University of Agriculture, Slovakia

Reviewed by: Javier de la Fuente California Polytechnic State University, United States

Michelle Lisa Colgrave,

Commonwealth Scientific and

Industrial Research Organisation (CSIRO), Australia

*Correspondence:

Oscar Zollman Thomas oscar@formo.bio

Specialty section: This article was submitted to Sustainable Food Processing, a section of the journal

Frontiers in Sustainable Food Systems

Received: 09 March 2021

Accepted: 04 June 2021

Published: 24 June 2021

Citation:

Zollman Thomas $O$ and Bryant $C$ (2021) Don't Have a Cow, Man: Consumer Acceptance of Animal-Free Dairy Products in Five Countries. Front. Sustain. Food Syst. 5:678491. doi: 10.3389/fsufs.2021.678491
Concern with the ethical, environmental and health consequences of the livestock industry is pushing the growth of a sector of animal-free alternatives. Advancing research is allowing these products to increasingly deliver experiences on a par with and beyond the products they originally sought to emulate, but widespread consumer adoption has not yet been realised. This research surveyed 5,054 individuals from Brazil, Germany, India, the UK and the USA, examining the nature and extent of acceptance of dairy products derived from precision fermentation, one of the three main pillars of alternative proteins. We find substantial consumer acceptance across countries for these products, animal-free dairy cheese, seeing $78.8 \%$ of consumers as probably or definitely likely to try such a product, with $70.5 \%$ probably or definitely likely to buy, substantially higher than previous research has found for cultivated meat products. Consumers anticipated animal-free dairy cheese to be significantly more tasty than current vegan cheese products, and just as tasty and safe as basic animal-derived cheese while rating it as significantly more ethical and environmentally friendly. Multiple linear regression revealed that within dietary identifiers, vegetarianism and veganism were strong predictors of willingness to buy but flexitarianism showed the strongest predictive power for willingness to buy. Of all variables, the strongest predictor of willingness to buy was current level of cheese consumption. Further regressions revealed that taste perception was key to driving purchase intent across all countries. The implications of these results for the development of the animal-free dairy sector are discussed.

Keywords: alternative protein, precision fermentation, cultivated dairy, cultured dairy, animal free proteins, cheese, future food, animal-free dairy

\section{INTRODUCTION}

Industrial animal agriculture is increasingly implicated as a root cause of many global problems. As well as having a substantial negative impact on the environment (IPCC, 2018; Poore and Nemecek, 2018; Clark et al., 2020), modern animal agriculture inflicts unnecessary suffering on animals (Pluhar, 2010; Anomaly, 2015) and exacerbates a variety of public health concerns including zoonotic pathogens and antibiotic resistance (Karesh et al., 2012; Landers et al., 2012; Machalaba et al., 2015). While consumers are increasingly aware of the ethical and environmental benefits of vegetarian and vegan diets, they largely prefer to continue eating animal products on the basis of price, taste, and convenience (Schenk et al., 2018; Bryant, 2019). Indeed, a UNDP (2021) survey found that while around two-thirds of the global population consider climate change an emergency, only $30 \%$ favoured a move towards plant-based diets to counteract this. 
Providing and promoting viable alternatives to animal products may be one of the most feasible strategies to address this paradigm. Following the proliferation of plant-based dairy alternatives, many companies have marketed plant-based meats, and these are increasingly consumed (The Good Food Institute, 2021) and increasing in their ability to satisfy consumers (Bryant and Sanctorum, 2021). At the same time, cultivated meat grown from animal cells has gone from a proof-of-concept in 2013 to market approval in 2020 (Bryant, 2020), and research on its adoption has proliferated in the past few years (Bryant and Barnett, 2018, 2020).

One category of future foodstuffs that has been relatively neglected is animal-free dairy, at the basis of which lies precision fermentation technology. Precision fermentation is the process of inserting specific genes into the DNA backbone of singlecell organisms and optimising the expression of the proteins that these genes code for. Precision fermentation is a longestablished technology, harnessed to synthesise compounds that would otherwise be expensive and complicated to acquire. Common examples of high-value materials derived from precision fermentation include insulin and rennet (a compound traditionally obtained from calf stomachs that even today is used in the production of many popular types of cheese), but as the costs associated with precision fermentation decline, the compounds this technology can produce will start to reach costcompetitiveness with a wider range of traditional materials. A number of companies, including the co-authors of this paper, Formo, are utilising precision fermentation to synthesise dairy proteins, creating a variety of products that will soon be cost-competitive with conventional dairy. In harnessing these production techniques dairy products are produced that are identical to conventional dairy in form, content, nutrition, and taste without the attendant issues of conventional dairy production (Datar et al., 2016).

Conventional dairy production entails processes that contribute to climate change, acidification, eutrophication, and ozone depletion (van der Werf et al., 2009; Djekic et al., 2014), and its overall carbon footprint is comparable to that of aviation and shipping combined (FAO, 2019; Ritchie and Roser, 2020).

The environmental impact of cheese, in particular, is higher per kilo than that of milk and yoghourt (Djekic et al., 2014). Life cycle assessments have estimated that, compared to conventional dairy products, animal-free dairy products use 65\% less energy, 91\% less land, and 98\% less water, while emitting $84 \%$ less greenhouse gases (Steer, 2015).

As well as environmental advantages, animal-free dairy circumvents the need to use animals, and the associated moral concerns (Milburn, 2018). In the dairy industry, female cows are repeatedly impregnated and have their calves taken from them at birth so that we can take their milk, causing great distress to both the mother and calf (see Lymbery and Oakeshott, 2014). Animal-free dairy products require no such process since they do not use animals.

Data indicates that dairy products seem to be particularly difficult to give up. In a survey of motivated vegans, vegetarians, and meat-reducers, Humane League Labs (2014) found that dairy was the food that respondents most often said they found hard to give up. Of respondents, $49 \%$ said that dairy was difficult to remove from their diet, compared to just $34 \%$ who said eggs were hard to avoid, $17 \%$ who said fish and seafood, $11 \%$ who said chicken, and just $3 \%$ who said beef and pork were challenging to abstain from. Similarly, Grassian (2020) identifies a hierarchy of foods that those reducing their animal product consumption prioritise and found that those abstaining from animal products were least likely to avoid dairy and eggs compared to other animal products. Therefore, it is likely that cheese is "the one food" that people wanting to make firm reductions in animal product consumption struggle most acutely to give up.

There is some research on consumer views of animalfree dairy products. The Grocer (2018) surveyed 1,061 UK consumers, finding that $28 \%$ said they would purchase "synthetic milk," 32\% said they would not, and 40\% were unsure. Interestingly, this data indicated higher acceptance of animal-free dairy than animal-free meat: the same organisation published comparable consumer data on the latter in 2017 (The Grocer, 2017), finding that just $16 \%$ of British consumers said they would eat cultivated meat. The types of concerns observed were similar: with respect to animal-free dairy, 50\% were worried about what chemicals or ingredients it would contain, $43 \%$ said it was unnatural, and $37 \%$ worried about possible long-term side effects.

However, the research on this topic is extremely limited, especially compared to consumer research on cultivated meat. The data cited from The Grocer (2018) is from a non-peer reviewed industry survey, only covers consumers in the UK, and gave participants some limited information on "synthetic dairy." Therefore, the present study sought to assess consumer acceptance of animal-free dairy in five key markets. In particular, we addressed the following research questions:

1. What is the overall level of consumer interest in animal-free dairy in Brazil, Germany, India, the United Kingdom, and the United States?

2. How do consumers in these countries perceive specific features of animal-free dairy, including taste, healthiness, and safety?

3. What differences are there between the five countries in terms of acceptance of animal-free dairy?

4. Which demographic factors and beliefs about animal-free dairy predict purchase intent in each country?

5. Which perceptions of animal-free dairy products predict purchase intent in each country?

\section{METHODS}

\section{Participants}

Participants were recruited from each of the five different countries via the research panels Dynata and SurveyGo. A redeemable points incentive, facilitated and distributed by the research panels, was paid out to respondents who fully completed the online survey - these incentives varied across countries and demographics and utilised research panels' reward systems to pay participants. We aimed to recruit a sample of 1,000 participants from each country in order to achieve good sample representativeness and sufficient power for between- and within-country analyses. The final sample size represented 5,054 
individuals, with 1,020 respondents from Brazil, 1,051 from Germany, 825 from India, 1,249 from the UK and 1,009 from the USA.

Four interlocking quotas per country (dictated by age and gender) were implemented by the panelling agency to ensure that samples were representative of true country populations. Despite this, the incidence rates amongst more granular groups, especially $18-25 \mathrm{~s}$ diverged from true population figures thus weightings were subsequently applied to generate results more accurately representative of whole country populations over the age of 18 .

Due to lower internet access and usage, particularly in India and Brazil, sampled populations from these countries skewed towards richer and more urbanised individuals in comparison to overall statistics for the respective populations at large. It is worth noting, however, that these demographic groups represent those most likely to be in a geographic and societal position to engage with, sample and purchase animal-free dairy products upon their imminent market arrival.

Participants who did not consent to take part in the study were removed from the survey, as well as those who failed at least one of two attention check measures that were interspersed throughout the survey. Whilst not initially designed to highlight fake or automated responses, three questions requiring text input from respondents also drew attention to fabricated responses, where automated machines filled out surveys to extract the incentive fee. These responses were often identically repeated between multiple observations and showed total irrelevance to the posed questions. Individual observations that exhibited answers such as these were removed from the dataset and replacement respondents were provided by the panelling agency. Across the five different countries, a total of 15,638 respondents were recruited to complete the survey. Once distilled by screener questions, quota limits and data quality checks, a final sample size of 5,054 was reached.

The initial screener prescribed spending sufficient time studying the 160-word background text on precision fermentation-derived protein manufacturing methods (determined as over 15 seconds). This screener question was deemed necessary for two reasons: to establish that the final sample represented individuals completing the survey in a sufficiently conscientious manner, and secondly to ensure that all participants gave responses in the context of requisite background information. The process of how this background information was formulated is discussed in section Materials. A total of 6,079 respondents were removed from the survey as a result of this screener. A further 734 respondents were removed from the survey for failing the second attention check, a question prompting them to select the indicated option from a possible five. A total of 3,325 respondents exceeded predetermined age and gender quotas and thus were redirected back to the panel. Lastly, 346 responses were removed manually for providing nonsensical or bot-generated text responses to the text entry questions. The propensity to be screened out at these stages was correlated with certain demographic traits, namely young male groups, and as a result, these groups were "topped-up" by the panelling agency to ensure as balanced samples as possible.

\section{Procedure and Measures}

This study received ethical approval from the Psychology Research Ethics Committee at the University of Bath. Participants used a checkbox on the questionnaire to indicate their informed consent in accordance with the Declaration of Helsinki.

Once consent was ratified, the initial section briefly outlined the background and purpose of the research project, as well as detailing data and anonymity protocols that would be followed with participants' data.

The next section asked for information regarding age and gender to facilitate redirects when demographic quotas were met.

The following section provided the requisite background information on the nature and processes involved in the production of animal-free dairy cheese. It is acknowledged that the framing of novel technologies, especially food products, significantly affects attitudes and acceptance rates of these products (Bryant and Dillard, 2019). Recognising this, the substance and formulation of the introductory passage were carefully considered, discussed fully in the Materials section.

The next section of questions gauged respondents' comprehension of the background information, with six questions checking their understanding in a series of true/false questions. When respondents selected the wrong answer this information was subsequently clarified in short bullet points. This resulted in all respondents ending with a roughly similar baseline understanding of the process of fermentation-based protein production and the traits of a product made through these means.

The following section posed the questions of how likely respondents would be to try, purchase and regularly purchase animal-free cheese products, with respondents choosing an answer on a 5-point semantic differential scale, corresponding to answers ranging from "Definitely Not" to "Definitely." Participants were then encouraged to write short and more nuanced answers to the questions surrounding their personal opinions on three aspects of animal-free dairy cheese and attitudes to their manufacture.

The next section measured respondents' dietary habits and behaviour, indicating how they define their diet, as well as describing their dietary habits in terms of consumption.

Respondents were then asked to rate various cheese products out of seven, across seven different attributes; tasty, ethical, environmentally friendly, natural, safe, healthy and nutritious. Each product was accompanied by a picture of an exemplar product, set against a neutral background, devoid of garnish or elaboration. Products were displayed in a randomised sequence to control for order effects. The animal-free cheese product was represented by an image of a standard depiction of mozzarella/paneer. This was deemed appropriate since animalfree dairy cheese products will bear a high likeness to traditional cheese products. The display of images and product ratings were conducted in the latter part of the survey so as not to condition the overall willingness to try and buy figures that respondents gave.

Demographic questions were then put to participants, including questions on education, political views, religiosity, degree of urbanisation and household income. 
Finally, respondents were asked a series of questions to gauge their opinions on a wider range of political and lifestyle themes, highlighting areas including neophobia, aversion to unnaturalness, trust in technology and attitudes towards climate change. Participants were then debriefed, thanked for their time, and redirected to the survey panels to receive compensation.

\section{Materials}

The conversation surrounding the nomenclature of animalfree dairy cheese has not yet gathered the same momentum nor research focus as the naming of clean-meat products, yet choosing and coordinating a name for this class of products remains an essential step in bringing animal-free protein products to market. This is all the more the case in light of the European Union's 2020 ruling, Amendment 171, to prohibit alternative-dairy products from being able to show their products in settings associated with conventional dairy products or even reference traditional dairy, especially regarding health or environmental comparisons. This is in addition to previous regulation from 2013 outlawing dairy-alternatives from being labelled with names such as soy-milk, butter or indeed, cheese. These pieces of legislation, strongly lobbied for by the dairy industry, are likely to undermine the EU's own environmental and public health targets (Southey, 2021). As part of the EU's Green Deal framework, the EU laid out a strategy seeking that "consumers should be empowered to choose sustainable food and all actors in the food chain should see this as their responsibility and opportunity," an aim which would, on the surface, run diametrically opposed to current regulation. Reflecting this political situation, this survey did not use any specific terminology while gauging consumer attitudes, seeking to avoid strongly colouring audiences' reactions to non-animal derived proteins. Instead, a theoretical cheese product was outlined, being launched by the company Legendairy Foods (the former company name of Formo). Rooting the decision facing respondents to a real, purchasable product provided conditions more familiar to audiences than an otherwise abstract scenario. For Brazil, Germany, the UK and the USA a mozzarella product was outlined to respondents. This was a decision taken in light of the global popularity of mozzarella cheese and the advanced development of this cheese by Formo and other animal-free cheese companies. Given the comparatively low annual sales of mozzarella in India, a paneer product was instead presented to respondents.

This product was thus simply referred to throughout the survey as "Legendairy Mozzarella/Paneer," avoiding intimidating and unappetising terminology, yet also avoiding the term "cheese." This description, providing the conditions for the results seen below, does undoubtedly build on consumers' expectations and understanding of animal-derived cheese products in a manner that the EU ruling attempts to suppress. The extent to which it will be possible to refer to animal-free protein products with the names of incumbent animal-based products is yet to be determined, but it would be expected that any lexical contortions mandated by government bodies would reduce the likelihood of the public opting to try animal-free dairy cheese products.
Similarly, the background information provided to respondents should be expected to acutely colour respondents' understanding and enthusiasm for animal-free dairy products. This survey sought to carve a middle path between anticipated narratives surrounding alternative protein, presenting a simple and transparent overview of the gene-editing technology and the processes involved in the development of animal-free dairy products, before drawing parallels to fermentation processes utilised in beer production. The passage highlighted the benefits of proteins generated through these techniques yet consciously avoided the hyperbole and fanfare likely to accompany pure marketing, instead seeking to depict a more detached snapshot of the conversation. The passage runs as follows:

\begin{abstract}
"Legendairy foods is launching a new mozzarella product, made without any animals involved.

Instead of relying on cows for milk, Legendairy uses a process similar to that of beer or soy-sauce production where microorganisms produce the ingredients. The main ingredients of traditional cheese are the proteins whey and casein - these are what the microorganism makes.

To begin this process, the part of cow DNA that makes milk proteins is copied and inserted into the microorganisms' genes.

Through fermentation, these microorganisms start to produce proteins, just the same as the proteins a cow would make. These proteins are collected from the microorganisms and turned into products such as mozzarella. Real protein and real mozzarella.

Legendairy mozzarella production doesn't involve any animals (nor the antibiotics that animals are often fed), doesn't contain lactose, has a much lower carbon footprint than regular cheese and it tastes and behaves exactly the same as regular mozzarella."
\end{abstract}

This information and the scenarios laid down by this research sought to simulate market conditions where animal-free dairy products are available, and where consumer awareness and understanding of these products is higher than it is currently.

The survey was distributed in three different languages, English, Portuguese and German throughout November and December 2020. The survey was translated into German and Portuguese through a process of back-translation to ensure the brevity and meaning of the survey was constant across countries. This was carried out by freelance translators based in Brazil and Germany, recruited through Fiverr. For the Indian survey, it was elected that English would be used for the distribution given the high degree of fluency amongst urban, younger generations, alongside the extreme diversity of languages spoken across India, even between immense urban centres (Salzmann et al., 2014). The questions shown to respondents were identical across countries aside from some demographic questions such as education and household income, which differed to reflect differences between the countries.

\section{RESULTS}

\section{Demographics}

Samples were weighted to be representative of national populations in terms of age groups and gender. The postweighting demographic variables were very closely representative of whole country populations in Germany, the UK and the USA. 
Tertiary education completion in the weighted sample for each of these countries was $30.7,50.0$, and $48.1 \%$ - corresponding to OECD figures of $28.58,45.96$, and $45.67 \%$ respectively. In India, the online polling led to fairly large divergences from population representativeness. $82 \%$ of the weighted sample were resident in big cities, whereas only $34.4 \%$ of the true population lives in urban areas with similar divergence seen in household income and education levels (World Bank, 2019). The Brazilian sample was much closer to representativeness in terms of urbanisation, yet did skew significantly more highly educated and with higher household income than the general population. These skews were expected in both Brazil and India. In Figure 1, the distribution of self-defined political affiliations across the countries is displayed, showing a relatively balanced distribution of conservative, moderate and liberal respondents within countries. Since participants were required to answer this question, it is possible that those indicating they are "moderate" represent those with no political opinions as well as "centrists."

\section{Overall Acceptance}

Strong enthusiasm for animal-free dairy cheese was demonstrated across all five countries; a majority of respondents in every country were not just willing to sample animal-free dairy cheese, but expressed a desire to purchase animal-free dairy cheese, with a total of $70.5 \%$ of the weighted samples stating they would probably or definitely buy such a product. Even when asked whether they would be likely to regularly purchase, an average of $49.8 \%$ of respondents from each country stated they would probably or definitely do so.

Figures 2-4 depict the extent of acceptance across the five individual countries. Enthusiasm was highly pronounced in Brazil and India, where respectively 92.0 and $93.4 \%$ of people would probably or definitely try animal-free dairy cheese. These numbers were lower yet still substantial for Germany, the UK and the USA where $75.9,67.6$, and $64.9 \%$ would probably or definitely try animal-free dairy cheese. When probing greater enthusiasm for animal-free dairy cheese, 85.5 and $91.1 \%$ of the Brazilian and Indian weighted sample would probably or definitely purchase an animal-free dairy product. In Germany, $62.7 \%$ claimed they would probably or definitely purchase an animal-free dairy cheese while in the USA and the UK, 53.8 and $58.5 \%$ deemed themselves as probably or definitely likely to purchase. Compared to the UK and Germany, the USA was on average slightly less enthusiastic, but exhibited more polarised responses, with a higher proportion of respondents at each end of the scale, stating in greater numbers that they would either definitely purchase or that they definitely would not.

The final question in this section asked participants whether they would be willing to regularly purchase an animal-free dairy cheese product. Despite inviting a substantial indication of commitment, a sizeable portion of respondents remained keen; $68.0 \%$ in Brazil, 36.1\% in Germany, $73.9 \%$ in India, 34.6\% in the UK and $36.3 \%$ in the USA stated they would probably or definitely regularly purchase animal-free dairy cheese. The weighted data here indicates a large tranche of populations across countries not knowing whether they would regularly purchase an animal-free dairy mozzarella, presumably needing to sample products before firmly committing to future behaviour.

\section{Product Perceptions}

The second portion of key variables captured respondents' perceptions of animal-free dairy cheese and several incumbent products across seven different areas, measured using a 7point Likert scale rating $(1=$ negative perception, $7=$ positive perception). Alongside animal-free cheese respondents were asked to rate "premium mozzarella/paneer," "basic supermarket mozzarella/paneer" and "vegan nut-based cheese."

All these products would be considered direct competition for animal-free dairy cheeses once they enter the market, thus the ratings depicted exhibit the basis on which consumers can be expected to embrace or reject animal-free dairy cheeses. Figure 5 depicts an overview of the aggregated ratings from all 5 countries for the different cheese types.

In terms of tastiness, animal-free cheese was rated across countries as being materially less tasty than the premium incumbent product, yet similar to a mass-market basic cheese product. In all countries, vegan nut-based cheese was rated significantly below all three alternative products, including animal-free cheese.

Across all countries, animal-free cheese was perceived clearly as the most ethical and environmental product that participants rated, followed by the nut-based vegan product. Premium and basic products were rated significantly behind animal-free cheese. In Germany and the UK especially, animal-derived cheeses were considered significantly less ethical and environmentally friendly than in the other countries.

Animal-free cheese was typically rated as the least natural of the four products apart from in Brazil, where animal-free mozzarella was considered as more natural than basic mozzarella and premium mozzarella, yet less natural than vegan nutbased cheeses. In Germany, the US and the UK, the perceived naturalness was lower than in the other countries, hovering just below the midpoint value of 4 . This juxtaposes with Brazil and India, where the average ratings were both above 5 out of 7.

Ratings of safety across countries followed a similar pattern, with both India and Brazil ranking animal-free cheese relatively highly in terms of safety, assessing it as safer than the basic incumbent product, higher than the premium product in Brazil and the vegan product in India. In Germany, the UK and USA animal-free cheese was clustered closely next to the vegan and basic products, albeit rated slightly lower. In all three of these countries, the premium product was dubbed the safest.

The rankings of healthiness and nutritiousness were generally similar between countries, with animal-free cheese rated similarly to basic cheeses and vegan nut-based options. The significance of these perceptions in driving consumption decisions is analysed in section Within Country Regressions.

Figure 6 shows a direct comparison in perceptions between an animal-free dairy cheese and a basic animal-derived mozzarella/paneer, with ratings for the basic product subtracted 

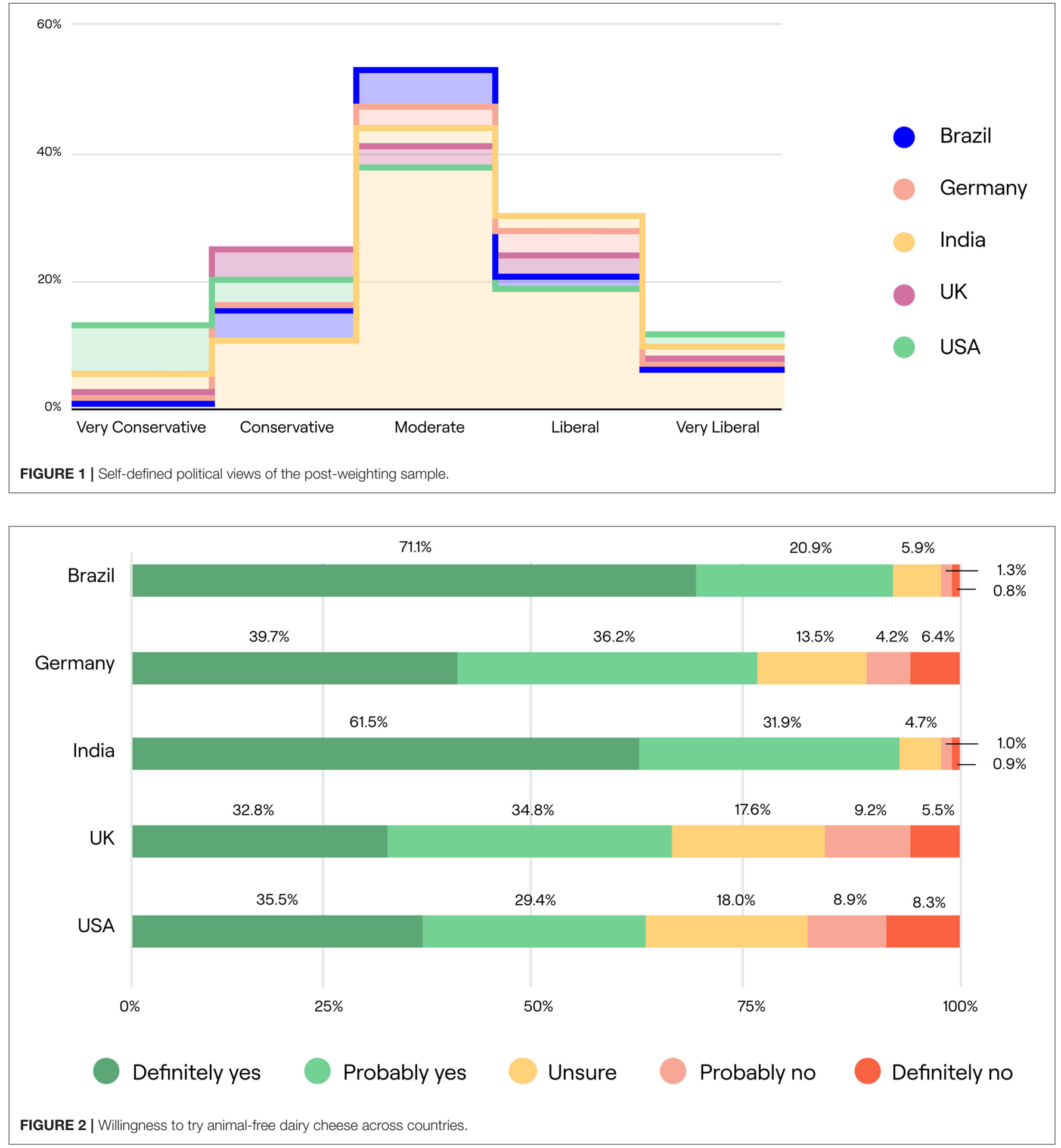

from the animal-free dairy product. The coloured lines represent the perceptions from across the five different countries. As discussed above, this figure illustrates how animal-free dairy is trusted to perform equally in terms of flavour, nutritional value and healthiness to basic mozzarella/paneer, yet is recognised to far exceed these basic cheeses in terms of ethical and environmental credentials. The graph further illustrates the varying strength of feeling across countries, showing Brazilian and Indian consumers as seeing the strongest advantages over basic animal-derived cheeses, but with respondents from all countries adjudging animalfree cheese as comparably nutritious, healthy and tasty as 


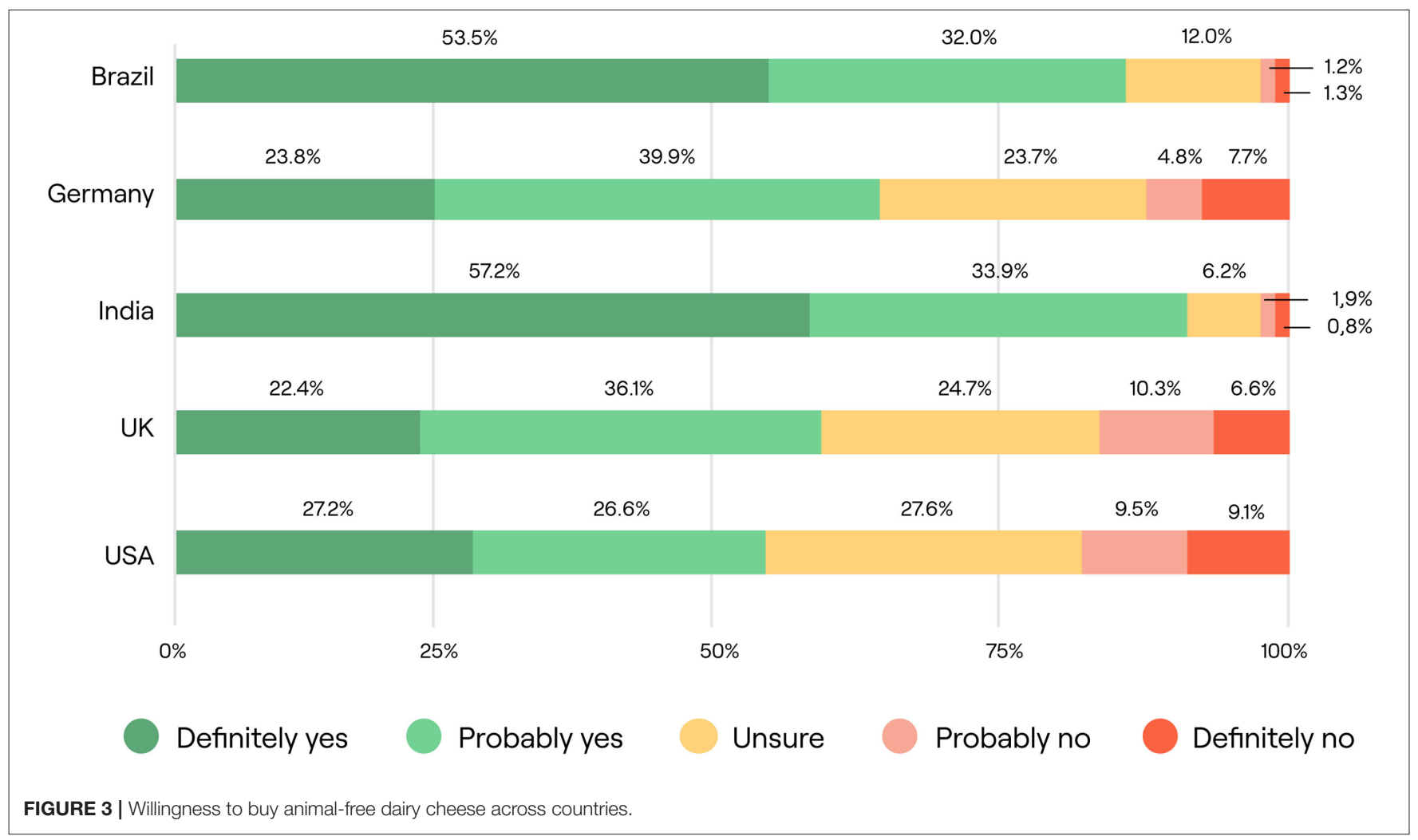

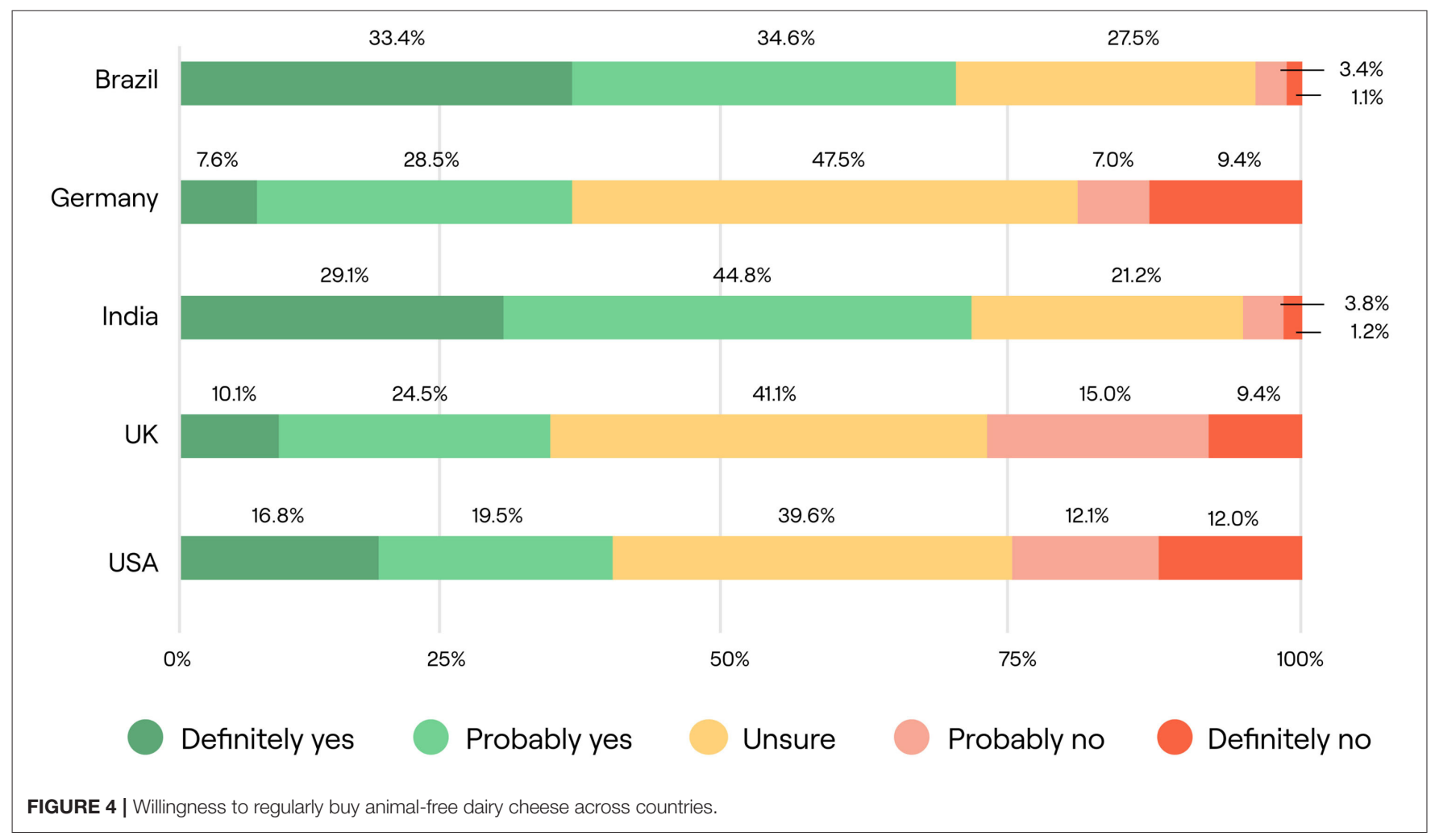



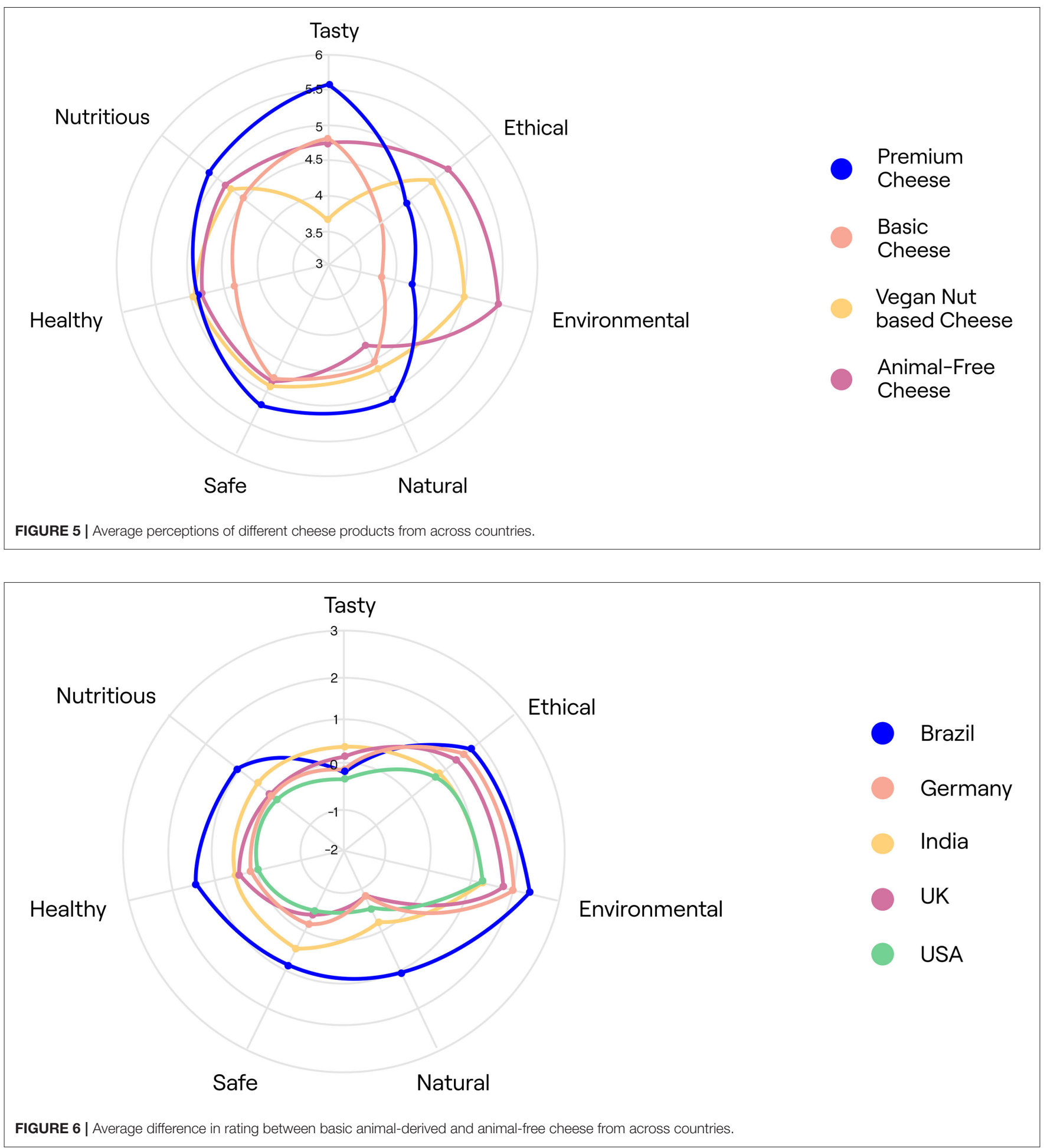

a basic animal-derived cheese. The product was noted as being distinctly less natural than basic cheese in all countries, apart from in Brazil where cheese produced using precision fermentation techniques was understood to be more natural than basic mozzarella.

\section{Cross-Country Comparisons}

Our next analyses compared the average responses given to questions about willingness to try, buy, and regularly buy animal-free dairy cheese across countries using a series of one-way ANOVAs. The results are shown in Table 1. 
TABLE 1 | ANOVAs showing differences between countries in animal-free dairy enthusiasm.

\begin{tabular}{lcccccc}
\hline & $\begin{array}{c}\text { Brazil } \\
\text { (M, SD) }\end{array}$ & $\begin{array}{c}\text { Germany } \\
(\mathbf{M}, \mathbf{S D})\end{array}$ & $\begin{array}{c}\text { India } \\
\text { (M, SD) }\end{array}$ & $\begin{array}{c}\text { UK } \\
\text { (M, SD) }\end{array}$ & $\begin{array}{c}\text { USA } \\
\text { (M, SD) }\end{array}$ & $\begin{array}{c}\text { ANOVA } \\
\text { Willing to try }\end{array}$ \\
\hline Willing to buy & $4.60^{\mathrm{a}}$ & $3.98^{\mathrm{b}}$ & $4.52^{\mathrm{a}}$ & $3.80^{\mathrm{c}}$ & $3.75^{\mathrm{c}}$ & $F_{(4,5164)}=151.812, p<0.001$ \\
& $(0.73)$ & $(1.13)$ & $(0.72)$ & $(1.18)$ & $(1.25)$ & \\
Willing to buy regularly & $4.35^{\mathrm{a}}$ & $3.67^{\mathrm{b}}$ & $4.45^{\mathrm{a}}$ & $3.57^{\mathrm{bc}}$ & $3.53^{\mathrm{c}}$ & $F_{(4,5164)}=176.949, p<0.001$ \\
& $(0.83)$ & $(1.12)$ & $(0.76)$ & $(1.14)$ & $(1.24)$ & \\
& $3.96^{\mathrm{a}}$ & $3.18^{\mathrm{b}}$ & $3.97^{\mathrm{a}}$ & $3.11^{\mathrm{b}}$ & $3.17^{\mathrm{b}}$ & $F_{(4,5164)}=186.091, p<0.001$ \\
& $(0.92)$ & $(1.00)$ & $(0.87)$ & $(1.08)$ & $(1.20)$ & \\
\hline
\end{tabular}

*Indicates significant differences between countries on this measure.

Lack of shared superscript letters indicate significant differences between particular countries.

Within each row, shared superscript letters indicate no significant difference between two values. Values which do not share a superscript letter are significantly different from one another. For example, in the second row, the score for the UK (marked with b and c) is significantly different from Brazil (marked with a only), while it is not significantly different from Germany (marked with b only) or the USA (marked with c only), though Germany and the USA differ from each other.

As shown, willingness to try, buy, and buy regularly, animalfree was generally highest in Brazil and India, followed by Germany, and lowest (although still above the midpoint of 3) in the UK and the USA. This confirms the differences observed in section Overall Acceptance and demonstrates which countries differ significantly in attitudes towards the products.

\section{Within Country Regressions}

Next, a series of linear regressions were generated to both identify the groups of consumers most likely to respond positively to the emergence of animal-free dairy cheese and the underlying product perceptions that contribute towards enthusiasm for the product. Regressions were run for each country individually, with willingness to buy used as the dependent variable, coding respondents' answers as 1 ("definitely would not purchase") to 5 ("definitely would purchase").

We ran two sets of regressions. In the first set of regressions, we entered demographics as predictor variables. These models were designed to identify the types of consumers most likely to purchase animal-free dairy. In the second set of regressions, we entered product ratings as predictor variables. These models were designed to identify the key attitudes and beliefs which drive purchase intent.

For the first set of regressions, 12 independent variables pertaining to gender, age, diet, degree of urbanness, religiosity, education and income levels were included, in addition to a variable that captured respondents' estimates of how often they consumed cheese. The results of these regressions are displayed in Table 2, with significant results highlighted.

The regressions reveal that the variable that offered the strongest predictor of a willingness to buy an animal-free cheese product was how frequently a respondent currently consumes cheese. This was the case across every country studied, indicating strong potential markets for animal-free dairy cheese far beyond the traditional markets served by non-dairy cheeses of vegans and those who are lactose intolerant. This relationship also counters an eventuality foreseen where "cheese purists" would reject cheese products made through precision fermentation; on the contrary, the opposite appears to be true. This relationship between cheese consumption and willingness to purchase animal-free dairy cheese was seen to be weaker in India than in the other studied countries, where there exists less of a cheese culture.

It was also indicated that younger consumers were more likely to be willing to purchase animal-free dairy cheese, mirroring findings from similar research on cultivated meat acceptance (Bryant and Barnett, 2020). This was true for every country apart from Brazil, where no significant relationship was found between age and willingness to buy. We found in Brazil that purchase intent was higher for women, yet this was the only country where a significant relationship was found between gender and purchase intent. Income was not a significant predictor of purchase intent in Brazil, India or the UK, but showed a slight negative relationship with purchase intent in Germany and the USA. Those identifying as more politically liberal indicated a higher likelihood of purchasing in the UK and USA whereas the opposite was true in Brazil where political conservatism was associated with an increased likelihood of purchasing animal-free cheese. It appears that the few objections to animal-free cheese came from very liberal people in Brazil.

In terms of an urban-rural divide in acceptance, no significant relationships were observed for Brazil, Germany, India or the USA, yet a small relationship was found between living in a more urban area and increased purchase intent in the UK. Level of education was not a strong predictor of acceptance in any country apart from India, where a strong positive relationship was observed between education and willingness to purchase. Religiosity had a weak positive relationship in the UK and a weak negative relationship in Germany. In other countries, no significant relationship was observed between religiosity and purchase intent.

Central to understanding the dynamics of consumer acceptance of animal-free dairy cheese is how association with different dietary groups affects product acceptance, especially in light of broad societal shifts in dietary patterns, particularly in the west (for example, the significant rise of flexitarianism, vegetarianism and veganism in the UK; Mintel, 2019). Treating omnivorism as a baseline, flexitarianism was the strongest 
TABLE 2 | Regression models showing demographic and dietary predictors (standardised $\beta$ ) of intention to purchase animal-free dairy cheese in Brazil, Germany, India, the UK and the USA.

\begin{tabular}{|c|c|c|c|c|c|c|c|c|c|c|}
\hline & \multicolumn{2}{|c|}{$\begin{array}{c}\text { Brazil } \\
\text { Adj } R^{2}=0.107\end{array}$} & \multicolumn{2}{|c|}{$\begin{array}{c}\text { Germany } \\
\text { Adj } R^{2}=0.087\end{array}$} & \multicolumn{2}{|c|}{$\begin{array}{c}\text { India } \\
\text { Adj } R^{2}=0.074\end{array}$} & \multicolumn{2}{|c|}{$\begin{array}{c}\text { UK } \\
\text { Adj } R^{2}=0.118\end{array}$} & \multicolumn{2}{|c|}{$\begin{array}{c}\text { USA } \\
\text { Adj } R^{2}=0.171\end{array}$} \\
\hline & Beta & $p$ & Beta & $p$ & Beta & $p$ & Beta & $p$ & Beta & $p$ \\
\hline Age & -0.01 & 0.736 & -0.111 & $<0.001$ & -0.095 & 0.01 & -0.084 & 0.003 & -0.182 & $<0.001$ \\
\hline Female & 0.091 & 0.003 & -0.043 & 0.164 & 0.059 & 0.08 & 0.015 & 0.591 & -0.045 & 0.137 \\
\hline Other gender & -0.01 & 0.745 & -0.043 & 0.155 & -0.008 & 0.81 & -0.05 & 0.071 & 0.002 & 0.951 \\
\hline Flexitarian & 0.131 & $<0.001$ & 0.21 & $<0.001$ & 0.076 & 0.04 & 0.164 & $<0.001$ & 0.151 & $<0.001$ \\
\hline Vegetarian & 0.134 & $<0.001$ & 0.09 & 0.003 & 0.018 & 0.62 & 0.063 & 0.021 & 0.069 & 0.017 \\
\hline Pescetarian & -0.045 & 0.129 & 0.07 & 0.019 & -0.016 & 0.64 & 0.066 & 0.015 & -0.032 & 0.274 \\
\hline Vegan & 0.049 & 0.098 & 0.068 & 0.025 & 0.064 & 0.06 & 0.027 & 0.313 & 0.043 & 0.14 \\
\hline Urbanness & 0.008 & 0.787 & -0.037 & 0.226 & 0.044 & 0.209 & -0.053 & 0.049 & -0.017 & 0.563 \\
\hline Education & 0.002 & 0.959 & 0.003 & 0.93 & 0.164 & $<0.001$ & -0.034 & 0.238 & 0.017 & 0.626 \\
\hline Political Views & -0.119 & $<0.001$ & 0.032 & 0.30 & 0.041 & 0.251 & 0.119 & $<0.001$ & 0.117 & $<0.001$ \\
\hline Religious & 0.001 & 0.969 & -0.065 & 0.03 & 0.042 & 0.234 & 0.086 & 0.002 & 0.012 & 0.689 \\
\hline Household Income & 0.013 & 0.695 & -0.052 & 0.11 & 0.064 & 0.083 & 0.07 & 0.014 & -0.057 & 0.093 \\
\hline Cheese consumption & 0.228 & $<0.001$ & 0.190 & $<0.001$ & 0.128 & 0.001 & 0.179 & $<0.001$ & 0.248 & $<0.001$ \\
\hline
\end{tabular}

Highlighted cells (where $p<0.05$ ) indicate that this variable significantly predicted purchase intent within the country.

dietary predictor of willingness to purchase in every surveyed country, with only cheese consumption providing a stronger overall predictor for animal-free dairy cheese preferences than flexitarianism. Notably, veganism, whilst a positive predictor for willingness to purchase, exhibited a weaker relationship than vegetarianism, pescetarianism or flexitarianism, aside from in India.

The second portion of the regression analyses focused on inherent product perceptions and how these predict purchase intent. These were rated by survey respondents on a scale from 1 to 7 . The $\mathrm{R}$ squared values for this set of regressions were higher than the demographic and dietary focused analysis, indicating that the perceptions of products form a stronger basis for acceptance than the intrinsic characteristics of individuals. The results of these regressions are depicted in Table 3.

Across all countries, higher perceptions of tastiness served as the strongest predictor of purchase intent, with the strongest effects seen in the UK and Brazil. This mirrors findings seen in research surrounding willingness to purchase cultivated meat, and points to the centrality of product performance in any future consumer shifts.

In Germany, India and the UK perceiving animal-free cheese as more ethical was a significant predictor of willingness to purchase, acting after tastiness as the strongest predictor of intention to purchase. In India and the UK, rating the product as more environmentally friendly predicted higher purchase intent, while in other countries significant differences in purchase intention were not observed as being dependent on differences in environmental friendliness perceptions. In the USA and UK, a weak but positive relationship was observed between perceptions of naturalness and intention to purchase. In the USA, perceptions of safety and healthiness also showed positive predictive power, with healthiness also observed as a significant predictor in
Germany. Nutritiousness was not a significant predictor in any of the surveyed countries.

\section{DISCUSSION}

This paper aimed to provide initial insight into anticipated consumer acceptance of animal-free dairy cheeses from across five different countries. In the absence of prior research into the acceptance of precision fermentation-derived consumer goods, the most consequential finding of this study is simply the scale and extent of consumer willingness to try, purchase and regularly purchase animal-free dairy cheese. Alongside this, the low levels of outright rejection ("probably" or "definitely not" trying amongst $2.1 \%$ in Brazil, $8.6 \%$ in Germany, $1.9 \%$ in India, $14.7 \%$ in the UK and $17.2 \%$ in the USA) provides an immensely strong signal that when animal-free dairy cheese products are made available they will address a diverse and fertile market, with the vast majority of populations across all surveyed countries open to trying such products and with a clear majority in every country stating that they would probably or definitely buy animal-free dairy cheese when it arrives on the market. These high levels of enthusiasm were particularly notable in Brazil and India, while acknowledging the skew towards urban and educated demographics within the sampled populations.

The evidence from this research suggests animal-free dairy proteins will help facilitate lifestyle shifts that can reflect public support for climate change mitigation, ethical concerns around the livestock industry and prevention of zoonotic diseases, with consumers seeing that animal-free dairy will allow a continuation of the most pleasurable aspects of their current diets while assuaging some of the most harmful effects of their current consumption. Tetrapak and Lund University collaborated in 
TABLE 3 | Regression models showing product characteristic predictors (standardised $\beta$ ) of intention to purchase animal-free dairy cheese in Brazil, Germany, India, the UK and the USA.

\begin{tabular}{|c|c|c|c|c|c|c|c|c|c|c|}
\hline & \multicolumn{2}{|c|}{$\begin{array}{c}\text { Brazil } \\
\text { Adj } R^{2}=0.232\end{array}$} & \multicolumn{2}{|c|}{$\begin{array}{c}\text { Germany } \\
\text { Adj } R^{2}=0.373\end{array}$} & \multicolumn{2}{|c|}{$\begin{array}{c}\text { India } \\
\text { Adj } R^{2}=0.192\end{array}$} & \multicolumn{2}{|c|}{$\begin{array}{c}\text { UK } \\
\text { Adj } R^{2}=0.391\end{array}$} & \multicolumn{2}{|c|}{$\begin{array}{c}\text { USA } \\
\text { Adj } R^{2}=0.383\end{array}$} \\
\hline & Beta & $p$ & Beta & $p$ & Beta & $p$ & Beta & $p$ & Beta & $p$ \\
\hline \multicolumn{11}{|l|}{ Constant } \\
\hline Tasty & 0.298 & $<0.001$ & 0.259 & $<0.001$ & 0.197 & $<0.001$ & 0.396 & $<0.001$ & 0.263 & $<0.001$ \\
\hline Ethical & 0.037 & 0.428 & 0.151 & 0.001 & 0.174 & 0.001 & 0.131 & 0.004 & 0.022 & 0.637 \\
\hline Envmnt & 0.048 & 0.286 & 0.008 & 0.842 & 0.096 & 0.048 & 0.108 & 0.014 & 0.026 & 0.571 \\
\hline Natural & 0.015 & 0.720 & 0.053 & 0.169 & 0.018 & 0.697 & 0.094 & 0.003 & 0.101 & 0.016 \\
\hline Safe & 0.026 & 0.643 & 0.073 & 0.125 & 0.041 & 0.529 & 0.045 & 0.261 & 0.111 & 0.044 \\
\hline Healthy & 0.094 & 0.145 & 0.181 & 0.001 & 0.000 & 1.000 & -0.075 & 0.091 & 0.149 & 0.029 \\
\hline Nutritious & 0.058 & 0.308 & -0.005 & 0.923 & 0.001 & 0.988 & 0.038 & 0.394 & 0.042 & 0.508 \\
\hline
\end{tabular}

Highlighted cells (where $p<0.05$ ) indicate that this variable significantly predicted purchase intent within the country.

2020 on research surrounding the evolution of the dairy industry, seeing the dual dimensions of technological transition and socioenvironmental forces as the key determinants of the extent of change in the dairy industry (Kalling et al.). Their research foresaw that should fermentation-derived dairy products gain both scaled-up technological viability and consumer acceptance, then between $35-50 \%$ of the 2030 dairy market could be sourced via animal-free dairy. Our research suggests that consumers will be receptive to dairy products made via precision fermentation, thus offering support for a forecast of a 2030 dairy market with animal-free dairy playing a sizeable role.

When juxtaposed against research into animal-free meat acceptance, the findings of this research suggest that animalfree dairy cheeses will see both faster adoption and less societal pushback than cultivated meat products. All of the countries examined in this research have previously been surveyed regarding preferences for cultivated meat:

- In Brazil, 63\% of consumers were found willing to try cellbased meat (Valente et al., 2019)

- In Germany, $57 \%$ of consumers were willing to try cultivated meat (Weinrich et al., 2020)

- In India, $48.7 \%$ of consumers said they would be very or extremely likely to purchase cultivated meat (Bryant et al., 2019)

- In the USA $65.3 \%$ of consumers would try In Vitro meat (Wilks and Phillips, 2017)

- In the UK $18.2 \%$ of consumers said they would be willing to try cultivated meat (SurveyGoo, 2018).

Apart from the US (where marginally stronger support for animal-free dairy was seen), markedly more enthusiasm for animal-free dairy was visible in every country when comparing to statistics for cultivated meat. Across Brazil, Germany, India and the UK, the present study observed substantially higher rates of acceptance for animal-free dairy. This mirrors a preference for animal-free dairy over cultivated meat in research by The Grocer $(2017,2018)$. The difference is perhaps due to decreased squeamishness in comparison to manufactured flesh or as a byproduct of consumers' acknowledgement of cheese as a product already deviating from food "as nature intended." Further, several studies have shown that familiarity with relevant food technologies is a strong predictor of willingness to consume food produced through novel means (Bryant and Barnett, 2020), thus as knowledge of precision fermentation technology increases, willingness to consume will likely rise in parallel. Recognising that dialogue surrounding cultivated meat has been more apparent and longstanding than that of precision fermentation made foodstuffs suggests that the margins between cultivated meat and animal-free dairy acceptance may reach even greater levels once animal-free dairy technologies become more prominent in public discourse.

A strong indicator that animal-free dairy products will intersect the dual desires of reduced planetary costs and an aversion to lifestyle sacrifices was shown within the regression analysis: a strong relationship emerging between current levels of cheese consumption and desire to purchase animal-free cheese. Rather than predicting an aversion to consuming nonanimal derived cheese, higher levels of cheese consumption were associated with an increased desire for animal-free dairy cheese. This suggests that animal-free dairy products can expect to see widespread market appeal, far beyond the niches of the current vegan cheese categories, and will likely see most interest from ardent cheese consumers seeking to reduce rather than eliminate their consumption of animalderived cheese.

Another stark finding was that, of all dietary variables, flexitarianism was the strongest predictor of willingness to buy, with large, statistically significant relationships observed in Brazil, Germany, the UK and the USA. Taken alongside the growing numbers of people identifying as flexitarian across the world (Bryant et al., 2020), this finding provides further evidence that many people will be ready to incorporate animal-free dairy products into their diet as part of an effort to reduce consumption of animal products. The fact that flexitarianism was associated with higher willingness to buy than veganism further indicates that animal-free dairy will be most enthusiastically adopted not by those who have already transitioned to plant-based diets, rather the larger group of consumers seeking to gradually modify 
their consumption patterns, maintaining some forms of animal products in their diet.

The linear regression model also revealed the wide demographic appeal of precision fermentation protein products, with either statistically insignificant or weaker effects indicated by the degree of urbanness, education, income and even political beliefs. When considering these findings together with the large outright percentage of society showing a willingness to purchase animal-free dairy products, it is apparent that even beyond diet, a diversity of consumers will be attracted to animal-free dairy. The weak statistical influence of the aforementioned variables shows that regardless of inherent characteristics, many understand the benefits of reducing consumption of animal products and consider animal-free dairy a feasible and attractive means of achieving this. While age was a strong predictor across countries and liberalness was associated with moderate predictive power in the UK and USA, the results mostly indicated that consumers from all kinds of groups are likely to be open to consuming animal-free dairy.

When studying the perceptions of animal-free dairy in comparison to incumbent products, consumers adjudge animalfree dairy products as comprehensively more environmentally friendly and more ethical than alternatives, including current vegan offerings. Given the background information provided, consumers expect animal-free dairy products to be less tasty than premium animal-derived products, substantially more tasty than vegan cheese products and comparably tasty to mid-market cheese products. Seeing this data in light of widespread product enthusiasm suggests a potential for animal-free dairy cheese to consolidate a commercial position as a mass-market product. The radar plot comparison against basic mozzarella further showed that respondents expect animal-free dairy cheese to be as tasty, as safe, more nutritious and healthier than basic cheese. These findings show the clear advantages consumers recognise of animal-free dairy over traditional products in several respects and add further colour to a picture showing consumers as trusting of precision fermentation technology to safely and nutritionally deliver a tasty product, which, when factoring in the acknowledged environmental and ethical upsides, results in the widespread willingness to purchase that was seen. This willingness to purchase rests heavily on these expectations which, seen in the second set of regressions, rests principally on taste. Meeting expectations of flavour and performance will thus be paramount for new products to deliver any major consumption patterns shifts.

There are several limitations to the present study worth noting. First, since there are no animal-free dairy cheese products currently available to consumers, we were only able to observe consumers' self-reported hypothetical preferences. Whilst we sought to lay bare the nature of animal-free dairy by providing a straightforward and neutral account of the process and its impacts, we are not able to account for how preferences may be shaped by future marketing efforts by animal-free dairy companies or indeed lobbying efforts against them. This research further took place in an unclarified legal environment, making it yet unclear as to what regulatory bindings will apply when animal-free dairy products reach market. Should particularly severe naming restrictions be applied to animal-free dairy then an encumbered consumer uptake of these new products could be anticipated. Further, although we made a good effort to obtain representative samples, some demographics were skewed, particularly in the Brazilian and Indian samples. That said, strong data quality protocols and participant rejection thresholds mean that the data quality is likely a strength of this study.

Future research should aim to expand on these findings, investigating in more detail the types of messaging and product positioning which may be optimal for animal-free dairy products. One particular area which needs further research is nomenclature; this has been an important issue in the cultivated meat field (Bryant and Barnett, 2019) but there is not yet comparable attention given to the naming of animalfree dairy.

\section{CONCLUSIONS}

As the cost of animal-free dairy ingredients decreases and their market debut approaches, this study offers the first comprehensive examination of how consumers will react to this new class of products, in particular cheese. The research found strong enthusiasm across countries for trying, buying and regularly buying animal-free dairy cheese products. An average of $78.8 \%$ of consumers across the five different countries defined themselves as probably or definitely likely to try such a product, with $70.5 \%$ probably or definitely intending to buy the product. This suggests the potential for a significant emerging role for animal-free dairy products in the wider cheese market, currently valued globally at US\$190.6 billion (Statista, 2020), with the capacity to massively expand the footprint of the current nonanimal cheese category, which has a current annual market value of US $\$ 1.2$ billion (Businesswire, 2020). The findings of this paper show the strongest enthusiasm and smallest opposition to animal-free dairy in Brazil and India, while also showing a majority of consumers in Germany, the UK and the USA as probably or definitely intent on purchasing animal-free dairy cheese products.

The findings of this paper also reveal the hurdles facing consumer acceptance of animal-free dairy to be substantially lower than those confronting cultivated meat products, notwithstanding that public awareness and discourse surrounding animal-free dairy is significantly less mature than that of cultivated meat, a factor which serves as a noted condition for widespread acceptance of novel technologies (Mutahar et al., 2018). This research similarly began to uncork the topic of why such clear consumer enthusiasm was observable, showing consumers across countries as resoundingly recognising the environmental and ethical improvements of animal-free dairy over animal-derived products, as well as showing faith in animal-free dairy to far outperform current iterations of plantbased cheeses, expecting a product capable of delivering a taste and nutritional experience similar to that of basic animal-derived products. In a similar way, consumers showed clearly that they did not perceive animal-free dairy to be any less safe than basic animal-derived products. 
More formally examining the relationship between perceptions and willingness to purchase revealed that perceptions of tastiness were key in determining willingness to purchase. Showcasing the flavour and functionality of animal-free dairy can thus be seen as a clear means to foster the uptake of animalfree dairy products amongst those still sceptical. Fortunately, the barriers to sampling animal-free dairy will be very low for consumers, providing the opportunity for consumers to make non-committal and low-cost "dabbles" before deciding whether to consume on a more long-term basis (Rogers, 2010).

This research also found that the strongest predictor of any outwardly observable variables were current levels of cheese consumption. Rather than showing the most ardent cheese consumers as averse to animal-free dairy products, this research found the opposite, highlighting both the openness of consumers to new products that can deliver familiar experiences and also showcasing that the market for animal-free dairy will be primarily driven by consumers not currently being served by the plantbased cheese sector.

Examining the demographic factors associated with willingness to purchase showed that diet was a strong predictor of enthusiasm, with flexitarianism serving as the strongest dietary predictor of willingness to consume. It can be anticipated that the advent of animal-free dairy will "ride the tide" of growing global numbers of flexitarians and consumers beginning to emotionally internalise the negative impacts of their consumption. Further, seeing flexitarianism as a stronger predictor of enthusiasm than veganism points to the prospect of animal-free dairy being embraced by societies transitioning in increments rather than absolutes, beginning to both ask more questions and seek more ownership and conviction in how and why they consume.

Whilst support trended younger in all countries, and with mild political effects seen in Brazil, the UK and the USA, an enduring takeaway of the demographic analysis points to a diversity in those expressing enthusiasm for animal-free dairy, with levels of education, income and urbanness either showing weak or statistically insignificant relationships with willingness to purchase. This points to both the potential breadth of acceptance across swathes of society and also the low potential for polarisation around the introduction of animal-free dairy. These findings serve as yet another strong indicator that societies will welcome the measured proliferation of precision fermentationderived products into their supermarkets, beyond their current accepted forms as functional ingredients or medicines.

As the public awareness surrounding animal-free dairy expands and dairy lobbies and regulator positions harden, further research will be necessary to map the trajectory of consumer

\section{REFERENCES}

Anomaly, J. (2015). What's wrong with factory farming? Public Health Ethics 8, 246-254. doi: 10.1093/phe/phu001

Bryant, C., and Barnett, J. (2018). Consumer acceptance of cultured meat: a systematic review. Meat Sci. 143, 8-17. doi: 10.1016/j.meatsci.2018.04.008

Bryant, C., and Barnett, J. (2020). Consumer acceptance of cultured meat: an updated review (2018-2020). Applied Sci. 10:5201. doi: 10.3390/app10155201 acceptance, but the research carried out here shows that any developments will take place against a backdrop of immense latent enthusiasm. It is this enthusiasm that shows consumers to be ready to embrace precision fermentation-derived products, products that will reduce the environmental burden of food production, alleviate animal suffering and drastically lengthen the odds of humanity's epidemiological dice games. The onus is now resoundingly on companies to service this demand and deliver products that can match the faith extended by consumers.

\section{DATA AVAILABILITY STATEMENT}

Data is not readily available to outside researchers. Requests to access the datasets should be directed to oscar@formo.bio.

\section{ETHICS STATEMENT}

The studies involving human participants were reviewed and approved by The Psychology Research Ethics Committee at the University of Bath. The patients/participants provided their written informed consent to participate in this study.

\section{AUTHOR CONTRIBUTIONS}

OZT: conceptualisation, translation, and data collection. CB and OZT: research design, survey instrument, data analysis, and writing manuscript. CB: ethics application. All authors contributed to the article and approved the submitted version.

\section{FUNDING}

Funding for this project was provided by Formo (previously Legendairy Foods), a company producing cheese products for consumers via precision fermentation.

\section{ACKNOWLEDGMENTS}

We would like to thank Jo Anderson for her advice in setting up the survey instrument and Raffa Wohlgensinger for the vision and drive to make it all happen!

\section{SUPPLEMENTARY MATERIAL}

The Supplementary Material for this article can be found online at: https://www.frontiersin.org/articles/10.3389/fsufs. 2021.678491/full\#supplementary-material 
Bryant, C., van Nek, L., and Rolland, N. (2020). European markets for cultured meat: a comparison of Germany and France. Foods 9:1152. doi: $10.3390 /$ foods 9091152

Bryant, C. J. (2019). We can't keep meating like this: attitudes towards vegetarian and vegan diets in the United Kingdom. Sustainability 11:6844. doi: $10.3390 /$ su11236844

Bryant, C. J. (2020). Culture, meat, and cultured meat. J. Anim. Sci. 98:skaa172. doi: $10.1093 /$ jas/skaa172

Bryant, C. J., and Barnett, J. C. (2019). What's in a name? Consumer perceptions of in vitro meat under different names. Appetite 137, 104-113. doi: 10.1016/j.appet.2019.02.021

Businesswire (2020). \$4.42 Billion Vegan Cheese Market - Global Opportunity Analysis and Industry Forecast 2021-2027. Available online at: https://www. businesswire.com/news/home/20201218005220/en/4.42-Billion-VeganCheese-Market---Global-Opportunity-Analysis-and-Industry-Forecast2021-2027---ResearchAndMarkets.com (accessed June 17, 2021).

Clark, M. A., Domingo, N. G., Colgan, K., Thakrar, S. K., Tilman, D., Lynch, J., et al. (2020). Global food system emissions could preclude achieving the $1.5^{\circ}$ and $2^{\circ}$ C climate change targets. Science 370, 705-708. doi: 10.1126/science.aba7357

Datar, I., Kim, E., and d'Origny, G. (2016). "New harvest," in The Future of Meat Without Animals, eds B. Donaldson, and C. Carter (Lanham, MD: Rowman and Littlefield), 121-131.

Djekic, I., Miocinovic, J., Tomasevic, I., Smigic, N., and Tomic, N. (2014). Environmental life-cycle assessment of various dairy products. J. Clean. Prod. 68, 64-72. doi: 10.1016/j.jclepro.2013.12.054

FAO (2019). Climate Change and the Global Dairy Cattle Sector - The Role of the Dairy Sector in a Low-Carbon Future. Rome: FAO.

Grassian, D. T. (2020). The dietary behaviors of participants in UK-based meat reduction and vegan campaigns-a longitudinal, mixed-methods study. Appetite 154:104788. doi: 10.1016/j.appet.2020.104788

Humane League Labs (2014). Large-Scale Survey of Vegans, Vegetarians, and Meat Reducers. Available online at: http://www.humaneleaguelabs.org/static/reports/ 2014/04/diet-change-and-demographic-characteristics1.pdf (accessed June 17, 2021).

IPCC (2018). Global Warming of $1.5^{\circ}$ C: An IPCC Special Report on the Impacts of Global Warming of $1.5^{\circ} \mathrm{C}$ Above Pre-industrial Levels and Related Global Greenhouse Gas Emission Pathways, in the Context of Strengthening the Global Response to the Threat of Climate Change, Sustainable Development, and Efforts to Eradicate Poverty. Intergovernmental Panel on Climate Change.

Kalling, T., Kärreman, M., Johansson, M., and Koch, C. (2020). Available online at: https://www.tetrapak.com/de/about-tetra-pak/news-and-events/newsarchive/ scenarios-future-dairy-industry

Karesh, W. B., Dobson, A., Lloyd-Smith, J. O., Lubroth, J., Dixon, M. A., Bennett, M., et al. (2012). Ecology of zoonoses: natural and unnatural histories. Lancet 380, 1936-1945. doi: 10.1016/S0140-6736(12)61678-X

Landers, T. F., Cohen, B., Wittum, T. E., and Larson, E. L. (2012). A review of antibiotic use in food animals: perspective, policy, and potential. Public Health Rep. 127, 4-22. doi: 10.1177/003335491212700103

Lymbery, P., and Oakeshott, I. (2014). Farmageddon: The True Cost of Cheap Meat. London: Bloomsbury Publishing.

Machalaba, C., Daszak, P., Karesh, W. B., and Romanelli, C. (2015). Anthropogenic Drivers of Emerging Infectious Diseases. United Nations Global Sustainable Development Report Briefs.

Milburn, J. (2018). Death-free dairy? The ethics of clean milk. J. Agric. Environ. Ethics 31, 261-279. doi: 10.1007/s10806-018-9723-x

Mintel (2019). UK Meat-Free Foods Market Report 2019. Available online at: https://www.mintel.com/press-centre/food-and-drink/plant-based-pushuk-sales-of-meat-free-foods-shoot-up-40-between-2014-19 (accessed June 17, 2021).

Mutahar, A. M., Daud, N. M., Ramayah, T., Isaac, O., and Aldholay, A. H. (2018). The effect of awareness and perceived risk on the technology acceptance model (TAM): mobile banking in Yemen. Int. J. Serv. Stand. 12, 180-204. doi: 10.1504/IJSS.2018.091840

Pluhar, E. B. (2010). Meat and morality: alternatives to factory farming. J. Agric. Environ. Ethics 23, 455-468. doi: 10.1007/s10806-009-9226-x

Poore, J., and Nemecek, T. (2018). Reducing food's environmental impacts through producers and consumers. Science 360, 987-992. doi: 10.1126/science.aaq0216
Ritchie, H., and Roser, M. (2020). Greenhouse Gas Emissions. Available online at: https://ourworldindata.org/greenhouse-gas-emissions (accessed June 17, 2021).

Rogers, E. M. (2010). Diffusion of Innovations. New York, NY: Simon and Schuster. Salzmann, Z., Stanlaw, J., and Adachi, N. (2014). Language, Culture, and Society: An Introduction to Linguistic Anthropology. New York, NY: Avalon Publishing.

Schenk, P., Rössel, J., and Scholz, M. (2018). Motivations and constraints of meat avoidance. Sustainability 10:3858. doi: 10.3390/su10113858

Southey, F. (2021). "Plant-based dairy censorship": Oatly, Upfield and ProVeg Petition to Overthrow Amendment 171. Food Navigator. Available online at: https://www.foodnavigator.com/Article/2021/01/14/How-Oatly-Upfield-andProVeg-plan-to-overthrow-Amendment-171 (accessed June 17, 2021).

Statista (2020). Consumer Market Overview, Cheese. Available online at: https:// www.statista.com/outlook/cmo/food/dairy-products- eggs/cheese/worldwide (accessed June 17, 2021)

Steer, M. (2015). A Comparison of Land, Water and Energy Use Between Conventional and Yeast-Derived Dairy Products: An Initial Analysis. Bristol: University of the West of England.

SurveyGoo (2018). Nearly One in Three Consumers Willing to Eat Lab-Grown Meat, According to New Research. Available online at: https://surveygoo.com/ portfolio/cultured-meat-survey/ (accessed June 17, 2021).

Tetrapak and Lund University (2020). Four Plausible Scenarios for the Future of the Dairy Industry. Available online at: https://www.tetrapak.com/content/dam/ tetrapak/publicweb/gb/en/about/future-dairy-exec-summary.pdf (accessed June 17, 2021).

The Good Food Institute (2021). Plant-Based Retail Market Overview. Available online at: https://gfi.org/resource/marketresearch/ (accessed June 17, 2021).

The Grocer (2017). Meat the Future... and How to Market It. Available online at: https://www.thegrocer.co.uk/meat/meat-the-future--and-how-to-marketit/546754.article (accessed June 17, 2021).

The Grocer (2018). "Test Tube Milk" More Likely to Win Brits Than Lab-Grown Meat. Available online at: https://www.thegrocer.co.uk/sourcing/test-tubemilk-more-likely-to-win-brits- than-lab-grown-meat/571598.article (accessed June 17, 2021).

UNDP (2021). The Peoples' Climate Vote. Available online at: https://www.undp. org/content/undp/en/home/librarypage/climate-and-disaster-resilience-/ The-Peoples-Climate-Vote-Results.html (accessed June 17, 2021).

Valente, J. D. P. S., Fiedler, R. A., Sucha Heidemann, M., and Molento, C. F. M. (2019). First glimpse on attitudes of highly educated consumers towards cell-based meat and related issues in Brazil. PLoS ONE 14:e0221129. doi: 10.1371/journal.pone.0221129

van der Werf, H. M., Kanyarushoki, C., and Corson, M. S. (2009). An operational method for the evaluation of resource use and environmental impacts of dairy farms by life cycle assessment. J. Environ. Manage. 90, 3643-3652. doi: 10.1016/j.jenvman.2009.07.003

Weinrich, R., Strack, M., and Neugebauer, F. (2020). Consumer acceptance of cultured meat in Germany. Meat Sci. 162:107924. doi: 10.1016/j.meatsci.2019.107924

Wilks, M., and Phillips, C. J. (2017). Attitudes to in vitro meat: a survey of potential consumers in the United States. PLoS ONE 12:e0171904. doi: 10.1371/journal.pone.0171904

World Bank (2019). Urban Population (\% of Total Population). Available online at: https://data.worldbank.org/indicator/SP.URB.TOTL.IN.ZS (accessed June 17, 2021).

Conflict of Interest: OZT was an employee of Formo (previously Legendairy Foods), a company intent on understanding and facilitating consumer interest in animal-free dairy. CB was the Director of Social Science at the Cellular Agriculture Society, which aims to promote cellular agriculture.

Copyright (c) 2021 Zollman Thomas and Bryant. This is an open-access article distributed under the terms of the Creative Commons Attribution License (CC BY). The use, distribution or reproduction in other forums is permitted, provided the original author(s) and the copyright owner(s) are credited and that the original publication in this journal is cited, in accordance with accepted academic practice. No use, distribution or reproduction is permitted which does not comply with these terms. 